\title{
Comprehensive Home Palliative Care Could Reduce Emergency Department Visits Due to Psychologic Dyspnea Among Cancer Patients: A Retrospective Cohort Study
}

\section{Hua-Shui Hsu}

Department of Palliative Medicine; Department of Family Medicine and Medical Research, China Medical University Hospital; Department of Family Medicine and Social Medicine, School of Medicine, College of Medicine, China Medical University

\section{Tai-Hsien Wu}

Department of Family Medicine and Medical Research, China Medical University Hospital https://orcid.org/0000-0002-3474-5428

\section{Chin-Yu Lin}

Department of Nursing, China Medical University Hospital

\section{Ching-Chun Lin}

Department of Family Medicine and Medical Research, China Medical University Hospital; Department of Family Medicine and Social Medicine, School of Medicine, College of Medicine, China Medical University

\section{Tsung-Po Chen}

Department of Family Medicine and Medical Research, China Medicinal University Hospital; Department of Family Medicine and Social Medicine, School of Medicine, College of Medicine, China Medical University

Wen-Yuan Lin ( $\square$ wylin@mail.cmu.edu.tw )

China Medical University Hospital

\section{Research article}

Keywords: dyspnea, home palliative care, emergency department

Posted Date: September 15th, 2020

DOI: https://doi.org/10.21203/rs.3.rs-70815/v1

License: (a) (1) This work is licensed under a Creative Commons Attribution 4.0 International License. Read Full License 
Version of Record: A version of this preprint was published on March 13th, 2021. See the published version at https://doi.org/10.1186/s12904-021-00713-6. 


\section{Abstract}

\section{Objective}

Dyspnea symptom is a common trigger of emergency department among the terminal illness and cancer patients. The frequent emergency department $(E D)$ visits at the end of life are the indicator of poor-quality care. We examine the emergency department visits rate due to dyspnea symptom among the palliative patients by enhanced home palliative care.

\section{Methods}

In our home palliative care team, patients are managed by palliative care specialists, residents, home care nurses, social workers, and chaplains. We enhanced the weekly home palliative care visit time from 5 days a week to 7 days a week, one to two times visit per week based on patient's need, to devise teambased medical services and formulate standard operating procedures for dyspnea care.

\section{Results}

Our team cared for a total of 762 patients with 512 ED visits, and 178 ED visits because of dyspnea (mean \pm SD age, $70.4 \pm 13.0$ years; $49.4 \%$ male). Dyspnea (27.8\%) was the most common reason recorded for ED visit, followed by pain (19.0\%), GI symptoms (15.7\%), and fever (15.3\%). The analysis of unexposed versus exposed groups revealed that the proportion of non-family workers (42.9\% vs.19.4\%) and family members (57.1\% vs. $80.6 \%)$ acting as caregivers significantly changed than basic $(P<0.05)$. Compared with ED visits of unexposed group, the risks evidently decreased $30.7 \%$ in exposed group $(P$ $<0.05)$.

\section{Conclusion}

This study proves that comprehensive home palliative care with add two days per week and formulate standard operating procedures for dyspnea could significantly reduce ED visits rate because of controllable dyspnea in the last six months of life.

\section{Introduction}

Home is the most common place of death for advanced cancer patients, and an important place of palliative care in Taiwan else ${ }^{1}$. The aim of palliative home care service is to improve the quality of life of patients with cancer and families without raising the total costs of care ${ }^{23}$. A palliative care team who is including specialist doctors, nurses, social workers, nutritionists and chaplains gives caregivers indispensable assistance about medical and emotion so that they can smooth transition palliative care from the hospital to home ${ }^{4}$. Otherwise, patients often seek urgent medical services for the emergency department (ED) ${ }^{5}$. 
The frequent emergency department visits at the end of life are the indicator of poor-quality care ${ }^{6}$. About four-fifth palliative care patients with advanced cancer repeated visits to the emergency department during the final six months of life ${ }^{7}$. However, nearly one-fourth of ED visits by palliative care patients may be avoidable ${ }^{8}$. For the family members, because their ability of clinical judgements are not enough, the patients makes more than one ED visit for the same condition ${ }^{9}$.

Dyspnea is one of the most common refractory symptoms in patients with advanced diseases, including cancer and non-cancer populations ${ }^{10}$. Previous studies show that the prevalence of dyspnea is higher than $50 \%$ among terminal illness patients and the cancer population ${ }^{11}{ }^{12}$. Dyspnea intensity and prevalence increase with disease progression, especially at the end of life; it may also leave devastating impacts on family and caregivers 71314 .

Dyspnea which is a complex symptom resulting from organic causes and psychologic distress need to be called for comprehensive evaluation and management of the condition ${ }^{15}$. Anxiety and panic are strongly correlated with psychologic dyspnea ${ }^{16}$. Oxygen therapy and low-dose sustained-related opioids play some roles in refractory dyspnea; nonpharmacologic treatment can also provide other benefits ${ }^{1718}$. A specialist palliative care team is necessary for managing patients with incurable dyspnea. In Taiwan, several medical centers have established well-trained home palliative care teams to provide medical, psychosocial, and spiritual support for terminally ill patients and their families. Early integration of palliative care could improve the quality of life by supporting patients through complex physical, psychosocial, and spiritual issues ${ }^{19-21}$.

However, few studies focus on the strategy for decreasing the suffering from dyspnea through home palliative care. The aim of the present study is to compare the two different approaches for dyspnea relief provided by our home palliative care team. The findings could reveal how the burdens of dyspnea patients can be reduced by home palliative care at their end of life and help promote successful experiences in future clinical practice.

\section{Methods}

\section{Study design}

This study was a retrospective cohort study in China Medical University Hospital, Taichung, Taiwan. Our patients who died with a primary diagnosis of cancer were from the linked hospital administrative databases during 2016-17.

\section{Study setting}

The cancer patients were referred from outpatient departments, oncology wards, and palliative care wards in China Medical University Hospital for consecutive home palliative care. On referral to home palliative care agency, the case manager recorded the basic information of patient such as sex, age, 
medical history, pathological condition, medication records, catheter location, emotion, family support and medical using location. The specialist home palliative care nurses would then visit the home to evaluate the home care needing, care plan, and visit frequency, caring for patient until death.

Our team members including family physician, home care nurses, social workers, and chaplains. A 24hour call line is available for phone consultations in home care team's office. According to the patients and family caregivers' requirements and clinical conditions, our home care team would arrange a visit once or twice a week. In addition, we offered the formal education information sheets on dyspnea management to family-caregivers to help them obtain organized content for home care (table 1)

\section{Selection criteria}

\section{Unexposed patients}

The basic home palliative care visit time was only five days per week (on Monday to Friday).

\section{Exposed patients}

In comprehensive home palliative care, the home palliative care visit time that was delivered seven days per week. We devised team-based medical services and gave training our home care team with formulate standard operating procedures for dyspnea care (table 2).

\section{Data source}

This study used the ED clinical data of cancer patients who received home palliative care in the final 6 months of life. The reasons for ED visits were anemia, altered mental status, catheter-related events, dyspnea, fell down, fever, N/V or other GI symptoms, pain, and tumor bleeding/complication. Patients ( $>18$ years old) with dyspnea who visited the ED within 3 days prior to death were excluded from this study (figure 1). The following data were extracted for each eligible participant: sex, age, educational status, religion, place of care, type of caregiver, number of nurse home visits and calls, major reasons for ED visit, and site of death.

\section{Statistical analysis}

A general linear model was used to compare group differences. All statistical analyses were performed using SPSS version 21.0 (SPSS, Inc., IBM Company, Chicago, IL, USA). All $P$ values were based on twotailed tests with statistical significance set at $<0.05$.

\section{Results}

During the study period from January 1, 2016 to December 31, 2017, our home palliative care team served a total of 762 patients with cancer: 374 was unexposed, and 388 was exposed. A total of $512 \mathrm{ED}$ visits were recorded, among which 178 visits were attributed to dyspnea. As ED visits due to dyspnea 
within 3 days before death were excluded from our analysis, a total of 106 visits were finally obtained (Fig. 1).

\section{Reasons For Visits To Ed}

Figure 2 summarizes the numbers and major reasons for ED visit. Dyspnea (27.8\%) was the most common reason recorded for ED visit, followed by pain (19.0\%), GI symptoms (15.7\%), and fever (15.3\%). Through improved home palliative care intervention, the percentage of ED visits due to dyspnea was lower than that in unexposed $(27.8 \%$ vs. $19.3 \%, P<0.05)$.

\section{Demographics Of Ed Patients With Dyspnea}

Table 3 depicts the characteristics of ED visits attributed to dyspnea under our home palliative care services. The total number of ED visits due to dyspnea was 106 (69 was unexposed, and 37 was exposed). The mean \pm SD age of the subjects was $70.4 \pm 13.0$ years, $49.4 \%$ man. The proportion of patient deaths at home in unexposed and exposed were $24.5 \%$ and $33.3 \%$, respectively. The majority of the caregivers of patients were migrant workers, companions, offspring and siblings of the patient; analysis exposed home palliative care revealed that the proportion of non-family workers $(42.9 \%$ vs. $19.4 \%)$ and family members $(57.1 \%$ vs. $80.6 \%)$ acting as caregivers significantly changed than unexposed $(P<0.05)$.

\section{Association Among Improve On Care Quality And Ed Visits}

Figure 3 further analyzes the risk of final ED visits due to dyspnea among home palliative care patients. Compared with ED visits of base, the risks evidently decreased $30.7 \%$ in comprehensive home palliative care $(P<0.05)$.

\section{Discussion}

Among the last six months of life in cancer patients receiving palliative home care, when additional home palliative care team intervention on the weekend were considered, these ED visits have significantly reduced approximately $30.7 \%(P<0.05)$ than standard palliative care. This study represents the effective home palliative care that could reduce the ED visits related to controllable dyspnea.

Besides the different pathophysiologies of various diseases, dyspnea is strongly correlated with mood distresses, such as anxiety, panic, and fear of suffocation, which may increase respiratory effort. The dyspnea crisis theoretical model indicated that dyspnea crisis most commonly occurs in unprepared and overwhelmed family-caregivers and chaotic setting ${ }^{22}$. Because dyspnea should be assessed by the individual experiencing it, the medical care team must understand the expectations and apprehensions of 
the patients and caregivers ${ }^{23-25}$. Given that dyspnea is multifactorial, a beneficial treatment strategy should include intervention to reduce anxiety and other psychological distresses ${ }^{26}$. In this study, detailed education sheets without bed-side evaluation by professional medical staffs could cause anxiety and confusion among caregivers, resulting in more ED visits.

Many ED visits (33.9\%) for cancer patients occurred on the weekend, although $44.9 \%$ occurred during clinic hours during the work week ${ }^{27}$. Some longitudinal surveys have observed that over half of all geriatric patients with advanced illness visit the ED in their last month of life and that repeat visits are common ${ }^{28} 29$. In the comprehensive palliative home care of this study, we extended extra working hours to Saturday and Sunday (8 am to $6 \mathrm{pm}$ ) for palliative home care. After we applied more frequent, comprehensive home palliative visits, ED visits due to controllable dyspnea episodes were obviously reduced $30.7 \%(P<0.05)$ than standard working hours; overall ED visits also significantly decreased. Multiple studies have shown similar results that patients receiving end-of-life nursing compared with standard nursing had decreased ED visits at last six months of life 3031.

ED visits can be a source of misery because of the crowded environment in hospitals, high patient-nurse ratios, and long waiting time, all of which can exhaust patients and their families. When death is imminent, ED is not the preferred place of death of patients ${ }^{32}$. Delgado-Guay and colleagues found that nearly one-fourth of all ED visits by patients with advanced cancer receiving palliative care could be avoided $^{8}$.

Moreover, increased intensity of home palliative care visits provided not only pharmacological consultation but also nonpharmacological interventions for dyspnea, such as improved air flow by fan, use of religious breathing exercises, adoption of a calm, reassuring attitude toward patients, comfortable positioning, a humane environment, and sustained safety to patients and caregivers. Similar to the findings of Sarmento VP and colleagues, coaching of caregivers and enhancing the experiences of patients and families are key factors in improving home hospice care ${ }^{33}$.

The preferred place to die is always at home, and achieving this preference is the goal in end-of-life care 2834 . In this study, success was reflected not only by the achievement of the reduced ED visits but also by the significant increase in proportion of families who participated in care responsibilities instead of nonfamily caregivers. (Table $1, P<0.05$ ) The aging trend and increase in cancer incidence are global issues.

The low birth rate, however, is also the current trend, whether the arrangement of qualified end-of-life care at home could impact family members requires further study.

\section{Limitations}

This study has some limitations. First, our hospital, a medical center, is located in an urban setting, and the patients we served lived within the area. Therefore, the present findings cannot reflect the accessibility of home palliative visit in rural areas. Second, this study was conducted in only one hospital. Replicated the outcomes in other institutions are important. Finally, further analysis was not conducted on the 
causes of dyspnea and their relationship with the patients' cancers because our study sample size is small. In future work, detailed evaluations with prolonged observation are recommended.

\section{Conclusions}

This study reveals that enhanced intensity of home palliative care visits could significantly reduce the number of ED visits because of controllable dyspnea at the end of life. Dyspnea is multifactorial, and an integrated treatment strategy should include intervention to reduce anxiety and other psychological distresses. Increasing palliative care services can give family-caregivers the confidence and courage to deal with end-of-life care, and more family members can participate in care.

\section{Declarations}

\section{Acknowledgements}

The authors gratefully acknowledge the staff of the home palliative care in hospital that provided the database for analysis.

\section{Author's contributors}

Study concept and design by HSH, THW, CYL, CCL, TPC. Drafting of the manuscript by HSH. THW completed the analysis. Critical revision of the manuscript for intellectual content by HSH, THW, WTL.

\section{Ethics approval and consent to participate}

This study was approved by the research ethics committee of China Medical University Hospital (CMUH108-REC3-008).

\section{Funding}

This study was supported by China Medical University Hospital, Taichung, Taiwan [grant number DMR104-071, DMR-104-072, CRS-105-173, and CRS-108-025].

\section{Competing interests}

None declared

\section{Consent for publication}

Not required

\section{References}


1. Chen $\mathrm{CH}$, Lin YC, Liu LN, Tang ST. Determinants of preference for home death among terminally ill patients with cancer in Taiwan: a cross-sectional survey study. J Nurs Res. 2014;22(1):37-44.

2. Gomes B, Calanzani N, Curiale V, McCrone P, Higginson IJ. Effectiveness and cost-effectiveness of home palliative care services for adults with advanced illness and their caregivers. Cochrane Database Syst Rev 2013(6):Cd007760.

3. Maetens A, Beernaert K, De Schreye R, Faes K, Annemans L, Pardon K, et al. Impact of palliative home care support on the quality and costs of care at the end of life: a population-level matched cohort study. BMJ Open. 2019;9(1):e025180.

4. National Institution of Aging. What Are Palliative Care and Hospice Care? Bethesda: National Institution of Health; 2017. Available from: https://www.nia.nih.gov/health/what-are-palliative-careand-hospice-care.

5. Solberg LM, Hincapie-Echeverri J. Palliative Care in the Emergency Department. Crit Care Nurs Clin North Am. 2015;27(3):355-68.

6. Earle CC, Park ER, Lai B, Weeks JC, Ayanian JZ, Block S. Identifying potential indicators of the quality of end-of-life cancer care from administrative data. J Clin Oncol. 2003;21(6):1133-8.

7. Barbera $L$, Taylor $C$, Dudgeon $D$. Why do patients with cancer visit the emergency department near the end of life? Cmaj 2010;182(6):563-8.

8. Delgado-Guay MO, Kim YJ, Shin SH, Chisholm G, Williams J, Allo J, et al. Avoidable and unavoidable visits to the emergency department among patients with advanced cancer receiving outpatient palliative care. J Pain Symptom Manage. 2015;49(3):497-504.

9. Mierendorf SM, Gidvani V. Palliative care in the emergency department. Perm J. 2014;18(2):77-85.

10. Laribi S, Keijzers G, van Meer O, Klim S, Motiejunaite J, Kuan WS, et al. Epidemiology of patients presenting with dyspnea to emergency departments in Europe and the Asia-Pacific region. Eur $\mathrm{J}$ Emerg Med. 2019;26(5):345-49.

11. Moens K, Higginson IJ, Harding R. Are there differences in the prevalence of palliative care-related problems in people living with advanced cancer and eight non-cancer conditions? A systematic review. J Pain Symptom Manage. 2014;48(4):660-77.

12. Bruera E, Schmitz B, Pither J, Neumann CM, Hanson J. The frequency and correlates of dyspnea in patients with advanced cancer. J Pain Symptom Manage. 2000;19(5):357-62.

13. Thomas S, Bausewein C, Higginson I, Booth S. Breathlessness in cancer patients - implications, management and challenges. Eur J Oncol Nurs. 2011;15(5):459-69.

14. Seow H, Barbera L, Sutradhar R, Howell D, Dudgeon D, Atzema C, et al. Trajectory of performance status and symptom scores for patients with cancer during the last six months of life. $\mathrm{J}$ Clin Oncol. 2011;29(9):1151-8.

15. Abernethy AP, Wheeler JL. Total dyspnoea. Curr Opin Support Palliat Care. 2008;2(2):110-3.

16. De Peuter S, Van Diest I, Lemaigre V, Verleden G, Demedts M Van den. Bergh O. Dyspnea: the role of psychological processes. Clin Psychol Rev. 2004;24(5):557-81. 
17. Pisani L, Hill NS, Pacilli AMG, Polastri M, Nava S. Management of Dyspnea in the Terminally III. Chest. 2018;154(4):925-34.

18. Nauck F, Alt-Epping B. Crises in palliative care-a comprehensive approach. Lancet Oncol. 2008;9(11):1086-91.

19. Higginson IJ, Bausewein C, Reilly CC, Gao W, Gysels M, Dzingina M, et al. An integrated palliative and respiratory care service for patients with advanced disease and refractory breathlessness: a randomised controlled trial. Lancet Respir Med. 2014;2(12):979-87.

20. Sorenson HM. Palliative care for lung disease: start early, stay late. Lancet Respir Med. 2013;1(4):279-80.

21. Ekström M, Allingham SF, Eagar K, Yates P, Johnson C, Currow DC. Breathlessness During the Last Week of Life in Palliative Care: An Australian Prospective, Longitudinal Study. J Pain Symptom Manage. 2016;51(5):816-23.

22. Mularski RA, Reinke LF, Carrieri-Kohlman V, Fischer MD, Campbell ML, Rocker G, et al. An official American Thoracic Society workshop report: assessment and palliative management of dyspnea crisis. Ann Am Thorac Soc. 2013;10(5):98-106.

23. Bausewein C, Calanzani N, Daveson BA, Simon ST, Ferreira PL, Higginson IJ, et al. 'Burden to others' as a public concern in advanced cancer: a comparative survey in seven European countries. BMC Cancer. 2013;13:105.

24. Grudzen CR, Richardson LD, Morrison M, Cho E, Morrison RS. Palliative care needs of seriously ill, older adults presenting to the emergency department. Acad Emerg Med. 2010;17(11):1253-7.

25. Calanzani N, Moens K, Cohen J, Higginson IJ, Harding R, Deliens L, et al. Choosing care homes as the least preferred place to die: a cross-national survey of public preferences in seven European countries. BMC Palliat Care. 2014;13:48.

26. Blinderman CD, Billings JA. Comfort Care for Patients Dying in the Hospital. N Engl J Med. 2015;373(26):2549-61.

27. Mayer DK, Travers D, Wyss A, Leak A, Waller A. Why do patients with cancer visit emergency departments? Results of a 2008 population study in North Carolina. J Clin Oncol. 2011;29(19):26838.

28. Smith AK, McCarthy E, Weber E, Cenzer IS, Boscardin J, Fisher J, et al. Half of older Americans seen in emergency department in last month of life; most admitted to hospital, and many die there. Health Aff (Millwood). 2012;31(6):1277-85.

29. Bell D, Ruttenberg MB, Chai E. Care of Geriatric Patients with Advanced Illnesses and End-of-Life Needs in the Emergency Department. Clin Geriatr Med. 2018;34(3):453-67.

30. Seow H, Barbera L, Pataky R, Lawson B, O'Leary E, Fassbender K, et al. Does Increasing Home Care Nursing Reduce Emergency Department Visits at the End of Life? A Population-Based Cohort Study of Cancer Decedents. J Pain Symptom Manage. 2016;51(2):204-12.

31. Sutradhar R, Barbera L, Seow HY. Palliative homecare is associated with reduced high- and lowacuity emergency department visits at the end of life: A population-based cohort study of cancer 
decedents. Palliat Med. 2017;31(5):448-55.

32. Gisondi MA. A case for education in palliative and end-of-life care in emergency medicine. Acad Emerg Med. 2009;16(2):181-3.

33. Sarmento VP, Gysels M, Higginson IJ, Gomes B. Home palliative care works: but how? A metaethnography of the experiences of patients and family caregivers. BMJ Support Palliat Care. 2017;7(4):0.

34. Kinoshita H, Maeda I, Morita T, Miyashita M, Yamagishi A, Shirahige Y, et al. Place of death and the differences in patient quality of death and dying and caregiver burden. J Clin Oncol. 2015;33(4):35763.

\section{Tables}

Table 1. Patient instructions for family-caregiver 
Phase 1. For restless and anxious individuals with respiration rate less than 20 times per min, follow the steps below:

1. Check if he or she is feeling unwell.

2. Use a fan or open the window to improve air circulation.

3. Massage the acupuncture points Lu 10 (Yuji), Lu 7 (Lieque) and ST36 (Zu San Li) or have him or her try to meditate.

4. Refrain from straining when urinating or defecating.

Phase 2. For individuals with respiration rate between 20-24 times per min, follow the steps below:

1. Check vital signs.

2. Check if he or she has been taking medications as prescribed.

3. In case of thick sputum, use an ultrasonic nebulizer for steam inhalation.

4. If necessary, clear sputum with sputum suction therapy.

5. Breath air in from the nose and breathe out from the mouth with a pursed lip.

6. Prepare to rent a medical oxygen generator in case oxygen therapy is needed.

7. Prepare to rent a medical oxygen generator in case oxygen therapy is needed.

8. Keep the patient accompanied.

9. Sit in a recline position or lie down with head elevated with cushioning to a 30-45 degrees angle.

10. Take extra precaution to protect the oral mucosa for mouth breathers.

Phase 3. For individuals with respiration rate more than 24-28 times per min or with sighing respiration (deep breaths), follow the steps below:

1. Check vital signs.

2. Check consciousness.

3. Check for death rattles.

4. Give oxygen therapy.

5. Consider giving medication for management of shortness of breath.

6. Call the palliative home-care nurse.

Please check the box after each step is completed, so the palliative home-care nurse can have a better understanding of the patient's conditions.

Table 2. Dyspnea and excessive sputum with difficult expectoration 


\section{Learning Goals}

1. Being able to list out current medications.

2. Assessment of dyspnea, labored breathing, excessive sputum with difficult expectoration, symptoms of deoxygenation.

3. Assessment of sputum amount, color, odor.

4. Management of acute dyspnea.

5. Management of excessive sputum and difficult expectoration.

Note. A. Lung primary cancer or metastases, compression of tumor mass on the airway, pulmonary infection, failure to clear sputum, heart failure, anemia and other situations may lead to dyspnea.

B. Timely management involves minimizing patient's fear, easing tension, and the use of simple yet appropriate methods to regain airway patency.

Table 3. Characteristic of ED patients with dyspnea attribute of the home palliative care patients in cancer.

\begin{tabular}{|lllll|}
\hline Characteristic & All sample & Unexposed & Exposed & $P_{\text {-value }}$ \\
\hline Patients, No. & 89 & 57 & 32 & \\
\hline ED visits & 106 & 69 & 37 & \\
\hline Man, No (\%) & $44(49.4)$ & $27(47.4)$ & $17(53.1)$ & 0.60 \\
\hline Age, mean \pm SD, yr & $70.4 \pm 13.0$ & $69.3 \pm 13.1$ & $72.6 \pm 12.7$ & 0.31 \\
\hline Grade of school completed, yr & $8 \pm 4.8$ & $8.4 \pm 4.4$ & $7.3 \pm 5.5$ & 0.32 \\
\hline Home care services & & & & \\
\hline Telephone nurse per weeks & $1.3 \pm 1.2$ & $1.4 \pm 0.8$ & $1.4 \pm 2.0$ & 0.95 \\
\hline Visiting nurse per weeks & $0.77 \pm 0.89$ & $0.75 \pm 0.4$ & $0.98 \pm 1.8$ & 0.32 \\
\hline Site of death & & & & 0.39 \\
\hline Home & $23(27.7)$ & $13(24.5)$ & $10(33.3)$ & \\
\hline Hospital & $60(72.3)$ & $40(75.5)$ & $20(66.7)$ & \\
\hline Types of Caregivers & & & & 0.027 \\
\hline Non-family & $30(34.5)$ & $24(42.9)$ & $6(19.4)$ & \\
\hline Family & $57(65.5)$ & $32(57.1)$ & $25(80.6)$ & \\
\hline
\end{tabular}


*ANOVA for continuous variables, chi-square test for categorical variables for the different palliative home care method.

\section{Figures}

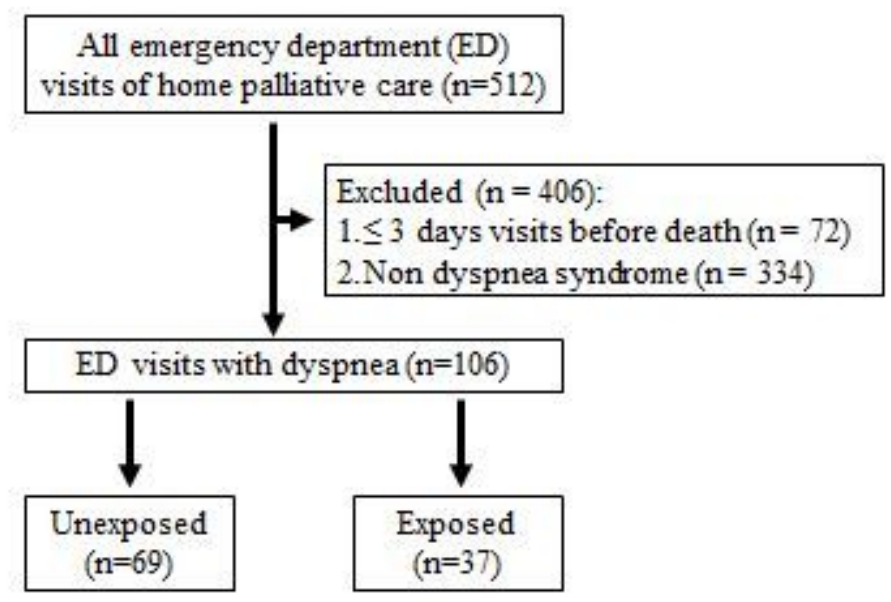

Figure 1

Study design

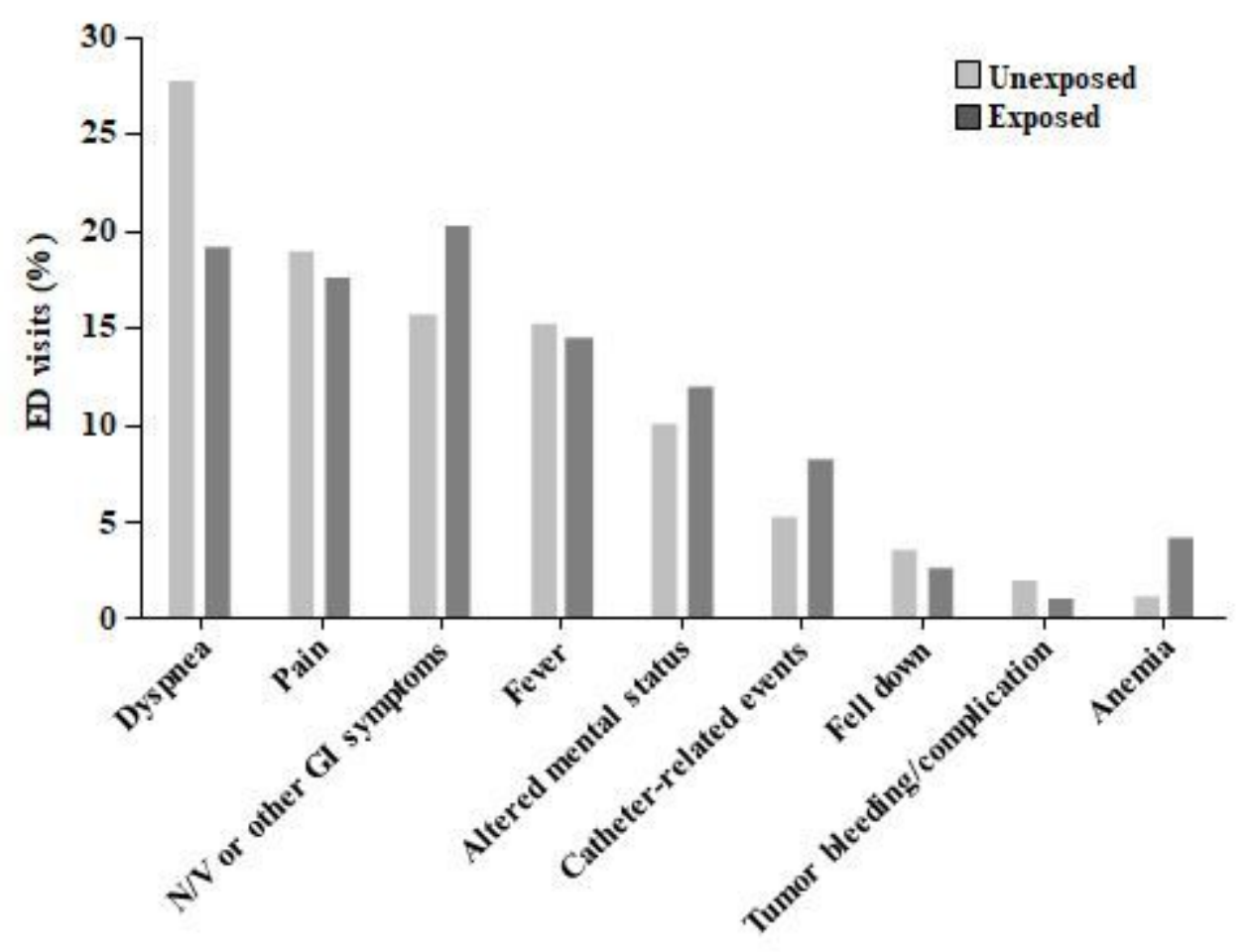

Figure 2

Reasons for visits to the emergency department (ED) by home palliative care patients in cancer. 


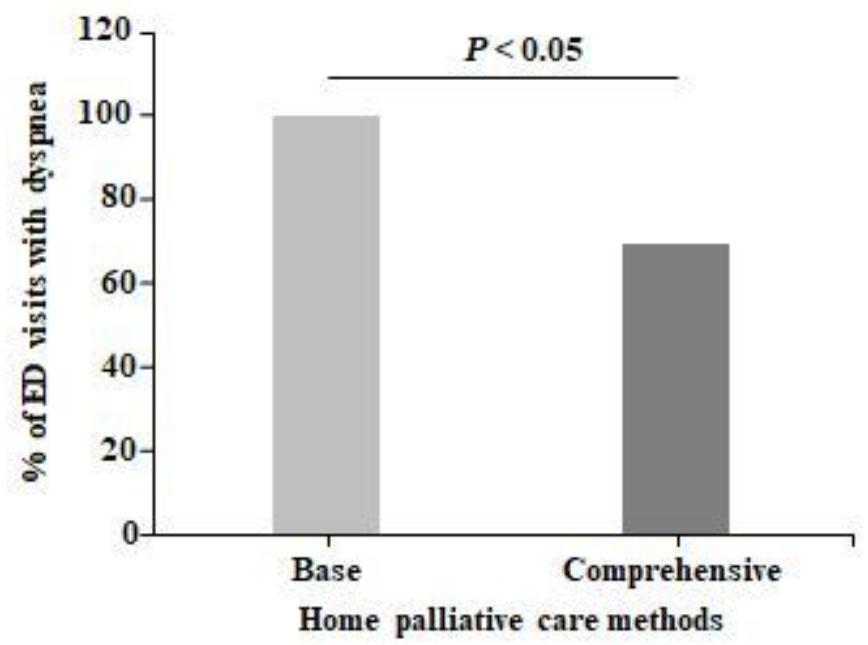

Figure 3

Proportion of ED visits with dyspnea in different home palliative care methods. 